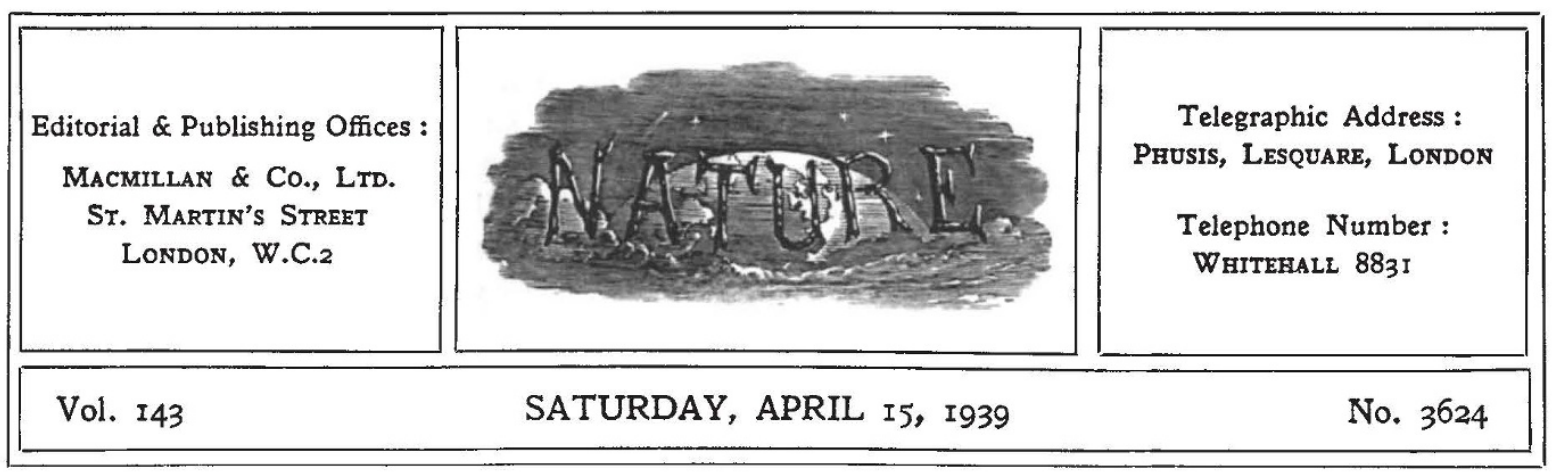

\title{
Education in a Democracy
}

A HOPEFUL effect of the challenge thrown ber last and in the events which have followed is the turning back to the beliefs and principles upon which our liberties are founded, and which are our justification for holding them and the frank facing of the issues involved. Men are freely recognizing that if the democracies are to withstand the challenge of the totalitarian regimes, with their threat to so much of the noblest in our heritage, it can only be as they prove themselves inherently superior and able by force of example as well as precept to check the ruthless doctrines which threaten alike the peace of the nations and the liberties of individuals. The survival of democracy depends on its ability to make constructive contributions in the present and future, not merely on its achievements in the past.

An admirable example of this tendency is to be found in the question of education, and especially education for citizenship. The certainty of aim of education under any form of dictatorship is a challenge to the educational systems of democratic countries which cannot be ignored. These systems produce citizens who believe the doctrines which their rulers wish them to believe, and are imbued with a fierce nationalism and devotion to the State. If we repudiate the charge that democratic systems produce pupils whose knowledge is unrelated to their country's needs, and whose minds are adapted for argument but not for loyalty or constructive criticism, we may fairly be asked what purpose or set of principles we have to set up against those of the authoritarian regime.

This, indeed, is a central problem of democracy to-day. It is an element of almost every question of national defence or preparedness for war, and the choice between a compulsory or voluntary national register will probably be determined by our efficiency in solving this problem. Essentially we require to define good eitizenship in a democracy, and to show how education can escape being an aimless pursuit of facts without becoming an instrument of propaganda. A significant section in the Spens Report points out that on the extent to which the youth of Great Britain can be fitted to fulfil later their duties and to take advantage of their opportunities as eitizens of a democratic State may well turn the whole future of democracy, and the report emphasizes the need for conscious effort by teachers at every point to use their opportunities.

An admirable discussion, by Michael Stewart, of the fundamental problem has been issued under the auspices of the Association for Education in Citizenship.* Under the title "Bias and Education for Democracy", Mr. Stewart gives us a highly suggestive and stimulating discussion of matters which are as relevant to the question of preserving freedom of thought and exposition as to teaching, and the wise and effective use of the opportunities which science no less than other subjects affords for training in citizenship.

Sooner or later, the difficulty of propaganda crops up, and Mr. Stewart meets it by a frank and careful analysis which deserves the attention of scientific workers, whether primarily concerned with the social sciences or not. $\mathrm{He}$ discriminates between two types of propaganda. The first, non-rational propaganda, aims at securing acceptance for certain views by appealing to the emotions and neglecting the reason, and sometimes * Oxford University Press. 
by vilifying opponents. This type is not confined to politics: much advertising material, though free from scurrility, is of this type, and whether in advertisement or in politics is frequently due to bias in the mind of the propagandist. While, however, propaganda may be a justifiable activity, biased judgment is at all times to be avoided, and it should not be confused with the deliberate selection which must be practised in teaching no less than in art or in science.

Rational propaganda, on the other hand, seeks support for a given view by marshalling reasoned arguments in its support, and fortunately there are both politicians and advertisers who use this method. Although its object is to serve a cause, it will not express opinions without examination of the facts so far as its time and ability permit. Where rational arguments are employed to propagate beliefs which represent the experience of the race, the resulting activity is certainly part of education and we might hesitate to call it propaganda. A sound principle may, however, be advocated by inaccurate or dishonest methods with results no less disastrous than attempts to propagate controversial views by rational methods.

Mr. Stewart accordingly stresses the danger of using ordinary lessons to propagate controversial opinions, even by rational methods, and in regard to the impartial presentation of controversial subjects stresses the need for handling such matters in a realistic way, even while excluding rational propaganda. He asserts indeed that this is the subject problem of the social sciences. Just as the teacher of chemistry, by putting acids and explosives into his pupils' hands, has an opportunity for training them in sensible conduct, so it is a positive advantage of the social sciences that they promote clear and unprejudiced thinking on disputed topics.

In the early stages of education some statements must be presented authoritatively as statements of fact; but even among beginners the use of authoritative statement has its dangers. A community which transmits its rules of conduct solely by authoritative teaching will make no progress towards a sounder moral judgment, and Mr. Stewart directs attention to possibilities in the use of broadcasting, the film, and dramatic work, as well as in the use of books which might make the promotion of right conduct attractive and interesting. The development of the critical process should begin at a comparatively early stage in education with the teacher's aid.
Especially are the social sciences important as vehicles for such training. From the study of human motives and actions in the past, the pupil sees that wisdom and honourable conduct are not the monopoly of those who hold a particular set of opinions. He becomes aware of the need for intellectual honesty and learns the nature of fair argument, and the difference between sound and unsound methods of proof. The power of rational criticism can, of course, be developed in many other subjects, such as the natural sciences. Dr. Thouless and Mr. Jepson have shown how accurate thinking can be taught at school, and Dr. Thouless ("Education for Citizenship in Secondary Schools", chap. xvi, p. 235) emphasizes that one object must be to create citizens intelligently approaching the problems of their citizenship and not young logicians or psychologists.

The essential point is that reasoning powers should be used not only to appraise the value of arguments, but also to handle facts and, if excessive effort is spent in encouraging criticism, education may produce only sceptics or persons without the power of decision. Life demands action as well as belief, and scepticism, if a necessary part of education, is by no means the only part. The pupil must learn how to act as well as to think for himself. Accordingly, Mrs. Wootten (Adult Education, Dec. 1937, pp. 96-7), in a plea for constructive teaching, urges that for a teacher to discuss any practical problem without, in the end, indicating what he himself thinks the best way of tackling it, is incompetent and irresponsible teaching.

Discussing the value of particular subjects in this respect, Mr. Stewart points out that, in teaching natural science, the social and economic effects of scientific discovery should be considered. Discussions on the effects of mechanized production on wealth and employment, and on the military use of scientific research, are often conducted by people who have little knowledge of the real possibilities. It should be the function of the teacher of science to remedy this defect. At least, he can equip his pupils to avoid the more serious errors of fact and reasoning, and can help them in the search for evidence. Science should be treated at the outset as a body of knowledge by which mankind can help itself.

Once again we encounter in this discussion the importance of training in the citizen's own language. Unless he can express himself clearly and attractively, a citizen cannot make a contribution 
to public life commensurate with his abilities. The purpose of democratic education, moreover, is human welfare, and this it is that dwarfs the narrow purpose of totalitarian education. Whatever impetus the enthusiasm of the dictatorship may give to society at first, there is no continuous springing up of new thought to give society flexibility and the power to adapt itself to changing circumstances. Influences which preserve society and sweeten life are cut off, and the State has no inherent principle of virtue.

The democratic citizen has the privileges and responsibilities of freedom; he is required to decide public policy and accept the consequences of his choice. Only in democracy can the teacher whole-heartedly see that his pupils get so much enjoyment from using their minds that they will not fear responsibility. Moreover, the teacher in a democracy must not fail to point out the mistakes of democracies in the past, whether the denial of elementary rights to subject peoples or the failure in foreign relations to accord to other nations the consideration and justice which their citizens displayed to each other at home.

Failure to understand that freedom means responsibility has brought about sloth and corruption which have paved the way for dictators, and scientific workers are no more free from responsibility for such failures than other classes of their fellow citizens. Mr. Stewart's lucid analysis of bias and propaganda indicates the causes of some of the defects in the teaching and exposition of science and the failure of scientific workers to make their full contribution in the solution of social and economic problems. At the least, it may be hoped that this admirable pamphlet will arouse them to a sense of the opportunities and responsibilities which are theirs, whether as citizens or as teachers of science, and to the resolute action which is demanded no less in the interests of scientific advance itself than in the safeguarding of those rich values of civilization which we owe to the freedom of thought and speech and criticism inherent in democracy alone.

\section{The Botany of Crop Plants}

Introduction to the Botany of Field Crops By Prof. J. M. Hector. (South African Agricultural Series, Vol. 16.) Vol. 1: Cereals. Pp. xii $+478+$ xiii-xxxiv. Vol. 2 : Non-Cereals. Pp. viii +479 1128+ix-xxxiii. (Johannesburg: Central News Agency, Ltd.; London: Gordon and Gotch, Ltd., n.d.) $70 s$. net.

THE plants making up the miscellany known I as 'field crops' are distributed throughout the families of the flowering plants almost haphazard. The qualities which make them valuable in industry or as food for man or stock, such characters as the production of fleshy roots or shoots, starchy or oily seeds, long fibres, etc., are usually of little or no importance to the botanist tracing phylogenetic relationships (although when correlated with wider ecological and soil studies they may be of fundamental interest) and, in consequence, the study of field crop plants has been seriously neglected by academic botanists.

During the last three decades, however, the study of field crops has been taken up by agricultural botanists, more especially in the United States, Germany and the U.S.S.R., but notably in Great Britain by Percival, and of many crop plants we now have a greater knowledge than of many plants of more theoretical interest. Much of this knowledge is of such a character that it could usefully and justifiably be incorporated in the pure botanical curriculum and the agricultural plants used as bases of study. If principles can be equally well exemplified in plants of great economic importance, it is surely better to use those plants in teaching than traditional examples of little or no human value.

Prof. Hector has aimed at surveying certain aspects of this field of work and, in his two imposing volumes, has presented in co-ordinated form a vast amount of information leading to an understanding of the nature and life processes of crop plants. His range covers field crops important as food for man or beast or valuable as producing economic fibres but, with the exception of the hop grown for brewing, he does not touch upon beverage plants or, with the exception of tobacco, upon medicinal and drug plants. Vol. 1 is devoted entirely to the Gramineæ, including the various temperate and semi-tropical cereals and sugarcane, but excluding pasture and other cultivated grasses. Vol. 2 covers a very wide field : the various root and cole crops, fibre plants such as hemp, flax and cotton, leguminous and other forage and oil-seed crops, and various oddments such as 